\title{
Evaluation of Advanced Stirling Convertor Net Heat Input Correlation Methods Using a Thermal Standard
}

Maxwell H. Briggs and Nicholas A. Schifer

Glenn Research Center, Cleveland, Ohio 


\section{NASA STI Program . . . in Profile}

Since its founding, NASA has been dedicated to the advancement of aeronautics and space science. The NASA Scientific and Technical Information (STI) program plays a key part in helping NASA maintain this important role.

The NASA STI Program operates under the auspices of the Agency Chief Information Officer. It collects, organizes, provides for archiving, and disseminates NASA's STI. The NASA STI program provides access to the NASA Aeronautics and Space Database and its public interface, the NASA Technical Reports Server, thus providing one of the largest collections of aeronautical and space science STI in the world. Results are published in both non-NASA channels and by NASA in the NASA STI Report Series, which includes the following report types:

- TECHNICAL PUBLICATION. Reports of completed research or a major significant phase of research that present the results of NASA programs and include extensive data or theoretical analysis. Includes compilations of significant scientific and technical data and information deemed to be of continuing reference value. NASA counterpart of peer-reviewed formal professional papers but has less stringent limitations on manuscript length and extent of graphic presentations.

- TECHNICAL MEMORANDUM. Scientific and technical findings that are preliminary or of specialized interest, e.g., quick release reports, working papers, and bibliographies that contain minimal annotation. Does not contain extensive analysis.

- CONTRACTOR REPORT. Scientific and technical findings by NASA-sponsored contractors and grantees.
- CONFERENCE PUBLICATION. Collected papers from scientific and technical conferences, symposia, seminars, or other meetings sponsored or cosponsored by NASA.

- SPECIAL PUBLICATION. Scientific, technical, or historical information from NASA programs, projects, and missions, often concerned with subjects having substantial public interest.

- TECHNICAL TRANSLATION. Englishlanguage translations of foreign scientific and technical material pertinent to NASA's mission.

Specialized services also include creating custom thesauri, building customized databases, organizing and publishing research results.

For more information about the NASA STI program, see the following:

- Access the NASA STI program home page at http://www.sti.nasa.gov

- E-mail your question via the Internet to help@ sti.nasa.gov

- Fax your question to the NASA STI Help Desk at $443-757-5803$

- Telephone the NASA STI Help Desk at 443-757-5802

- Write to: NASA Center for AeroSpace Information (CASI) 7115 Standard Drive Hanover, MD 21076-1320 
NASA/TM-2012-217293

AIAA-2011-5578

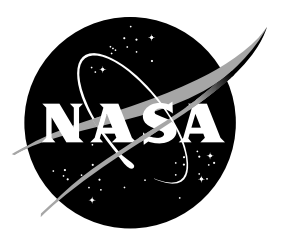

\section{Evaluation of Advanced Stirling Convertor Net Heat Input Correlation Methods Using a Thermal Standard}

Maxwell H. Briggs and Nicholas A. Schifer

Glenn Research Center, Cleveland, Ohio

Prepared for the

9th International Energy Conversion Engineering Conference (IECEC)

sponsored by the American Institute of Aeronautics and Astronautics

San Diego, California, July 31-August 3, 2011

National Aeronautics and

Space Administration

Glenn Research Center

Cleveland, Ohio 44135 


\section{Acknowledgments}

This work is funded through the National Aeronautics and Space Administration (NASA) Science Mission Directorate and the Radioisotope Power Systems Program Office.

This report contains preliminary findings, subject to revision as analysis proceeds.

Trade names and trademarks are used in this report for identification only. Their usage does not constitute an official endorsement, either expressed or implied, by the National Aeronautics and Space Administration.

Level of Review: This material has been technically reviewed by technical management.

Available from

NASA Center for Aerospace Information 7115 Standard Drive

Hanover, MD 21076-1320
National Technical Information Service 5301 Shawnee Road Alexandria, VA 22312

Available electronically at http://www.sti.nasa.gov 


\title{
Evaluation of Advanced Stirling Convertor Net Heat Input Correlation Methods Using a Thermal Standard
}

\author{
Maxwell H. Briggs and Nicholas A. Schifer \\ National Aeronautics and Space Administration \\ Glenn Research Center \\ Cleveland, Ohio 44135
}

\begin{abstract}
The U.S. Department of Energy (DOE) and Lockheed Martin Space Systems Company (LMSSC) have been developing the Advanced Stirling Radioisotope Generator (ASRG) for use as a power system for space science missions. This generator would use two high-efficiency Advanced Stirling Convertors (ASCs), developed by Sunpower Inc. and NASA Glenn Research Center (GRC). The ASCs convert thermal energy from a radioisotope heat source into electricity. As part of ground testing of these ASCs, different operating conditions are used to simulate expected mission conditions. These conditions require achieving a particular operating frequency, hot end and cold end temperatures, and specified electrical power output for a given net heat input. In an effort to improve net heat input predictions, numerous tasks have been performed which provided a more accurate value for net heat input into the ASCs, including testing validation hardware, known as the Thermal Standard, to provide a direct comparison to numerical and empirical models used to predict convertor net heat input. This validation hardware provided a comparison for scrutinizing and improving empirical correlations and numerical models of ASC-E2 net heat input. This hardware simulated the characteristics of an ASC-E2 convertor in both an operating and non-operating mode. This paper describes the Thermal Standard testing and the conclusions of the validation effort applied to the empirical correlation methods used by the Radioisotope Power System (RPS) team at NASA Glenn.
\end{abstract}

\section{Nomenclature}

$\begin{array}{ll}\text { ASC } & \text { advanced Stirling convertor } \\ \text { CSAF } & \text { cold side adapter flange } \\ \text { EL } & \text { environmental losses, } \mathrm{W} \\ \text { FEA } & \text { finite element analysis } \\ \text { HET } & \text { hot-end temperature, } \mathrm{K} \\ \text { HST } & \text { heat source temperature, K } \\ \text { GHI } & \text { gross heat input } \\ \text { NHI } & \text { net heat input, W } \\ \text { R } & \text { thermal resistance between the heat source and hot end, K / W }\end{array}$

\subsection{Introduction}

Convertor efficiency is a crucial performance parameter that must be accurately measured in order to guarantee that the Advanced Stirling Convertor (ASC) will meet its performance specifications. Central to the determination of convertor efficiency is an accurate estimate of net heat input (NHI) to the convertor. The NHI of an operating convertor cannot be measured directly, because the amount of heat being leaked to the environment (environmental losses (EL)) cannot be distinguished from the heat input to the thermodynamic cycle. However, stalled (non-operating) convertors have no contribution from the thermodynamic cycle, making it possible to estimate what portion of the gross heat input (GHI) that is 
attributed to EL. Therefore, correlations for EL can be made based on non-operating data. These correlations can then be applied to operating convertors as long as the relationship between EL and the correlation parameters does not change substantially once the piston is in motion. Several different parameters including cold-end temperature and GHI were initially considered as potential inputs to the environmental loss correlation, but hot-end temperature (HET) and heat source temperature (HST) were found to be the only substantial contributors and will be the only ones discussed in this paper. The correlation methodology is described mathematically below:

$$
\begin{gathered}
\mathrm{EL}_{\text {non-operating }}=\mathrm{f}(\mathrm{HET} \text { and/or HST })_{\text {non-operating }} \\
\mathrm{EL} \text { operating }=\mathrm{f}(\mathrm{HET} \text { and/or HST })_{\text {non-operating }}+\text { Difference } \\
\mathrm{NHI}=\mathrm{GHI}-\mathrm{EL} \text { operating }
\end{gathered}
$$

Where EL is environmental losses, HET is the hot-end temperature, HST is heat source temperature, Difference is the inaccuracy resulting from applying the non-operating correlation to operating data, NHI is net heat input, and GHI is the gross heat input measured directly as the electrical power to the heat source. For this method to be used effectively, EL of the non-operating convertor must be accurately characterized using the chosen correlation parameters (typically HET, HST, or some linear combination of the two) and the difference term in Equation (2) must be within an acceptable tolerance. The Thermal Standard can be used to test both of these assumptions.

A commonly used method of developing correlations for the EL of a non-operating convertor was referred to as the alumina disk testing. This test involved placing a convertor into the insulation package, with a thin alumina disk between the heat source and the hot end, and measuring the GHI required to achieve various HETs and HSTs. During alumina disk testing, the GHI to the heaters minus the amount of heat conducted through the convertor to the cold-side adapter flange (CSAF) is calculated as the EL. The heat conducted through the convertor can be calculated using relatively simple conduction equations, and the electric input to the heaters can be directly measured, so the heat lost through the insulation at a given operating condition can be calculated. The limitation of this method is that when the convertor is not operating and it is not pulling heat out of the heater, there is a very small temperature difference across the alumina disk from the heat source to the hot end. Operating convertors see a much larger temperature difference across these components, with HSTs of around $100{ }^{\circ} \mathrm{C}$ for a nominal HET of $842{ }^{\circ} \mathrm{C}$. Because the insulation package sees a much different temperature gradient across the convertor during operation than it does during the alumina disk testing, it is possible that Equation (2) will not be satisfied. Specifically one would expect empirical correlations based on HET data of a non-operating convertor using an alumina disk to underpredict EL, because the correlation assumes that both the HST and HET are close to the hot-end operating temperature of $842{ }^{\circ} \mathrm{C}$. Likewise, empirical correlations based on HSTs are expected to overpredict EL, because these correlations assume that the heat source and HET are both close to the HST of $1000^{\circ} \mathrm{C}$. In addition to these biases, temperature limitations on the ASC-E2 heater head prevent data from being taken on a non-operating convertor with the heat source near its expected operating temperature of $1000{ }^{\circ} \mathrm{C}$. Therefore, empirical correlations based on the HST must be extrapolated to predict the EL of operating convertors, which is expected to result in some additional error.

Another empirical modeling method, referred to as thermal barrier testing, simulates the heat-sourceto-hot-end temperature difference of an operating convertor while testing a non-operating convertor. During thermal barrier testing, ceramic paper insulation is inserted between the heat source and the convertor hot end. Introducing this insulation creates a substantial temperature difference between the heat source and convertor hot end, similar to that seen in an operating convertor, even though the convertor is idle. This makes it more likely that the difference term in Equation (2) is sufficiently small, and eliminates the need to extrapolate the HST-based correlations as is required in alumina disk testing. The primary limitation of thermal barrier testing is that in order to run an ASC-E2 convertor after a thermal barrier test, the insulation package must be partially disassembled to remove the barrier prior to operating the convertor. This could result in changes in the setup of the insulation package that could change the difference term in Equation (2). 
To resolve the limitations of thermal barrier testing, a new method was developed in which heat lost through the insulation was calculated numerically using finite element analysis (FEA). This modeling methodology begins with a generic model of the GRC insulation package. This generic insulation model is then tuned to the specific insulation package using alumina disk test data. This tuned insulation model is then used to predict the heat lost through the insulation for an operating convertor, based on temperature profiles measured during convertor operation. This method allows the EL and NHI to be calculated without disassembling the insulation package and does not require empirical EL correlations to be generated and/or extrapolated. The disadvantage of using an FEA model for calculation of EL and NHI is the time that it takes to set up, calibrate, and run the model, which can delay the results. Real-time estimates of NHI will have to be made using empirical correlations described above in order for convertor operators to set operating points, and these estimated values will have to be refined at a later time using the FEA model.

By simulating both non-operating and operating convertors and allowing for NHI to be calculated in both cases, the Thermal Standard allows the predictions of each of the correlation methods described above to be compared to test data, thus quantifying any inaccuracies. The application of the Thermal Standard to FEA model validation can be found in Reference 1.

\subsection{Thermal Standard Design}

The design of the Thermal Standard is based on the mock heater head concept and the lessons learned from a series of mock heater head tests (Ref. 2). These lessons learned resulted in several improvements in the design of the Thermal Standard. These improvements include precise replication of ASC-E2 heater head external geometry, closer replication of the ASC-E2 heat transfer path, improved instrumentation, the ability to compensate for uncertain values of contact resistance, and the use of the high-temperature, high-conductivity material GRCCop-84 (Refs. 3 and 4) to remove heat from the Stirling hot end.

Conceptually, the Thermal Standard is a replica of an ASC-E2 heater head assembly brazed to a modified CSAF. A schematic of the Thermal Standard can be seen in Figure 1; because of export control restrictions, a corresponding schematic of the ASC-E2 heater head is not included. To reduce cost and schedule, the Mar-M portions of the heater head were replaced with 316L stainless steel. 316L stainless steel was chosen because it has a thermal conductivity that is close to Mar-M, and because it resists oxidation at the required temperatures. The variable thickness wall of the ASC-E2 heater head was replaced with a constant thickness wall for ease of fabrication and to allow for simple one-dimensional hand calculations of heat flow through the wall to be made. The internal acceptor on the inside of the heater head was replaced with a piece of solid nickel with a conical hole. This conical hole provides a high surface area mate for a cylindrical rod with a conical tip, which is put in place to conduct heat, simulating the thermodynamic heat draw of an operating convertor.

The cylindrical rod that interfaces with the Thermal Standard is designed to conduct the same amount of heat that passes through the acceptor of an operating ASC-E2 convertor. Figure 2 shows a full assembly of the Thermal Standard with rod and heat exchanger in place. During testing, the actual heat throughput of the rod can be calculated using simple one-dimensional conduction equations based on a measured temperature gradient. It should be noted that the most accurate measurement available for the conductivity of the rod based on a laser flash method performed by the Thermophysical Properties Research Laboratory was \pm 4 percent. Consequently, each calculation of heat through the rod based on temperature measurements also has an uncertainty of \pm 4 percent.

The Thermal Standard closely replicates the geometry, heat transfer path, and temperature profile seen in an actual convertor, it is placed inside an ASC-E2 insulation package, and it allows for simulation of both a non-operating and an operating convertor. Therefore, NHI models can be compared directly to NHI calculations made from measured temperature gradients on parts with a simple and well-defined geometry. 


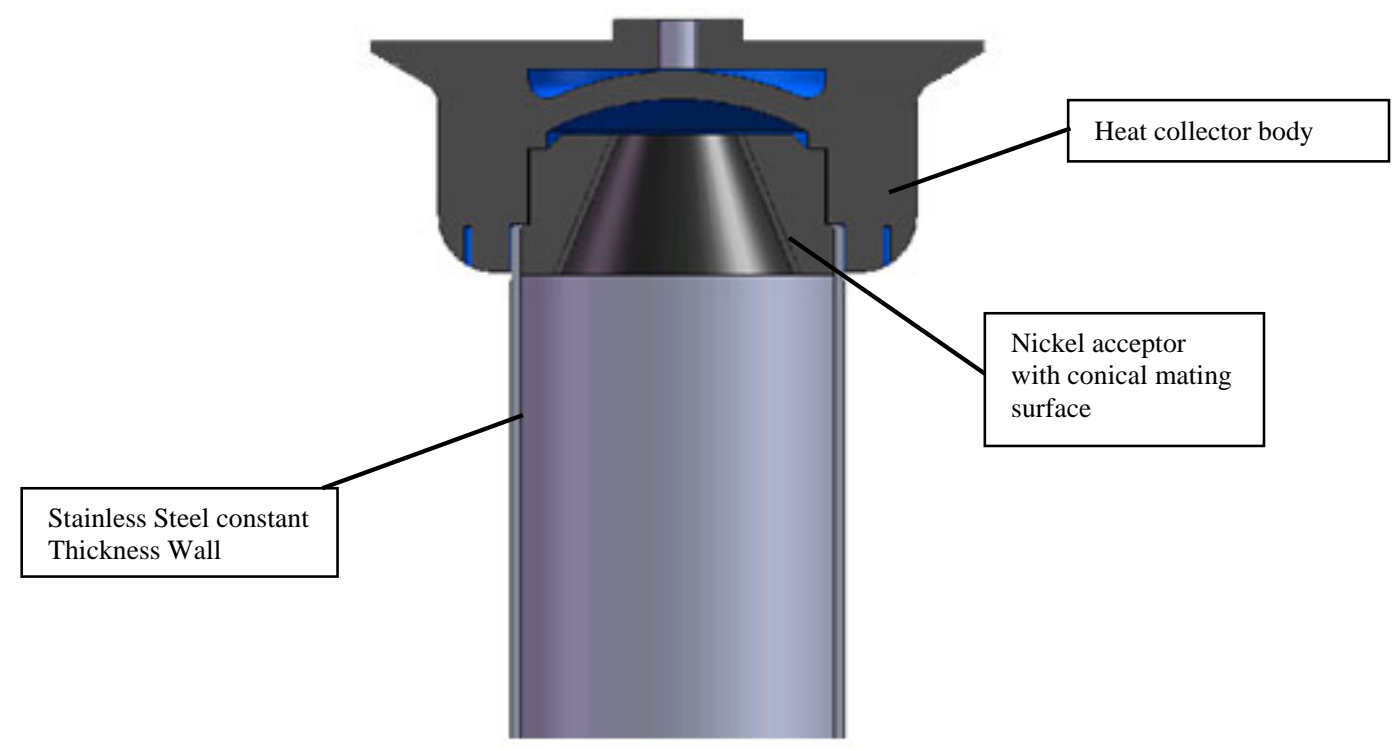

Figure 1.-Cross-section of Thermal Standard heater head.

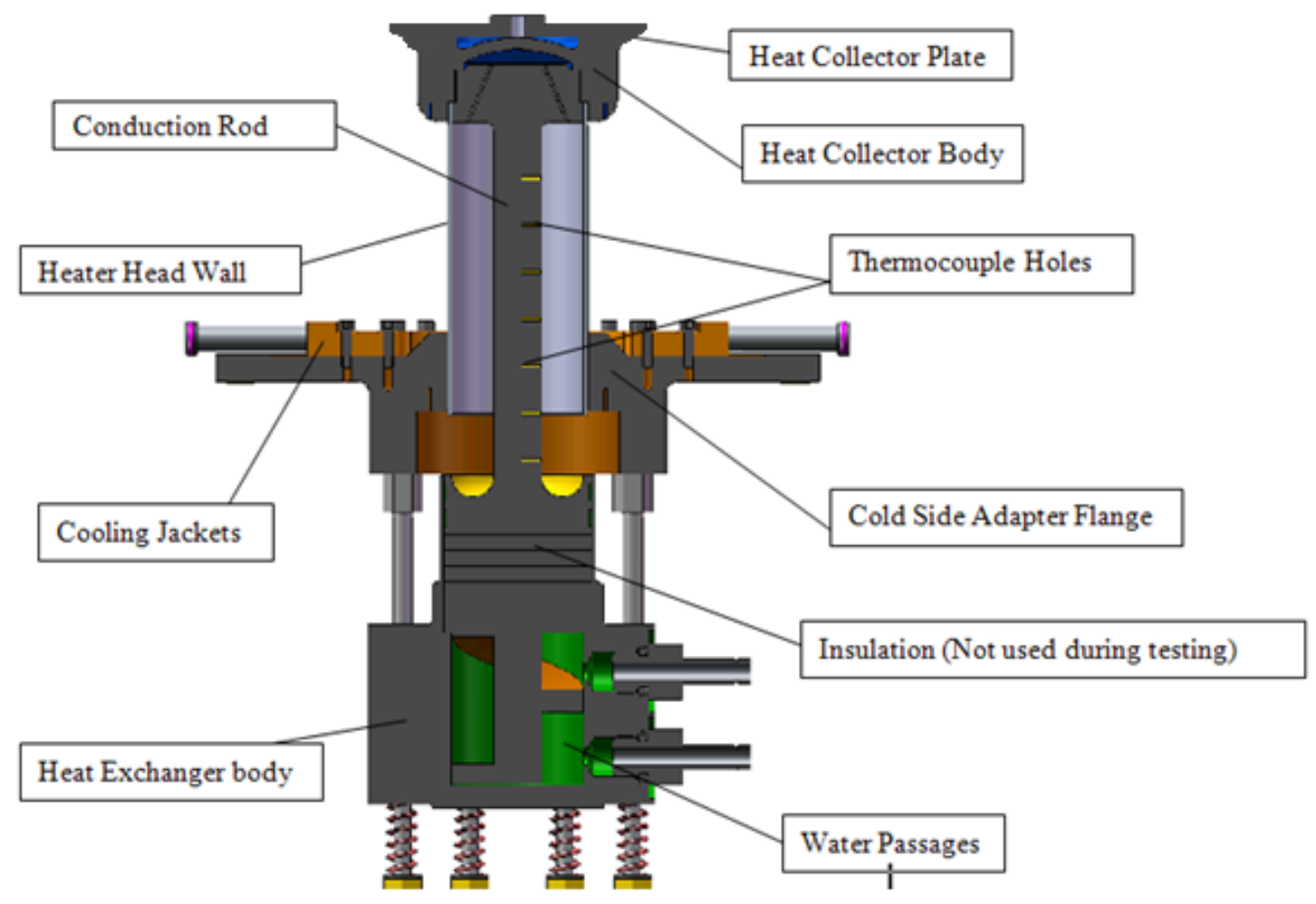

Figure 2.-Cross-section of Thermal Standard in the simulated operation configuration. 


\subsection{Methodology}

The Thermal Standard went through the same test sequence as an actual ASC-E2 convertor. The ASC-E2 test sequence begins with alumina disk testing, in which heat is applied to a non-operating convertor through a range of HETs. Heat flow within the convertor is then calculated by measuring convertor temperatures and using conduction and radiation equations to determine cold-end losses through the heater head walls, regenerator, helium gas, and displacer. These losses typically total approximately $17 \mathrm{~W}$. Subtracting these cold-end losses from the measured GHI gives the EL of a nonoperating convertor at a given HST and HET. These results are then used to tune FEA models and build empirical correlations for individual ASC-E2 convertors.

Alumina disk testing was simulated on the Thermal Standard by measuring temperatures and heat flows through a range of HETs without a rod in place, as shown in Figure 3. With no rod to conduct heat, the only available heat transfer paths are through the heater head wall and through the insulation package to the environment. The temperature gradient on the heater head wall was measured, and Fourier's law was used to calculate the conduction through the walls, which was typically around $20 \mathrm{~W}$. This allows the EL to be calculated as the difference between the GHI and the heat conducted through the wall using methods very similar to those used during ASC-E2 alumina disk testing.

Similarly, thermal barrier testing is accomplished on ASC-E2 convertors by inserting insulation between the heat source and the Thermal Standard hot end and operating through a range of HSTs without a rod in place. EL can then be calculated in the same way as alumina disk testing. To simulate thermal barrier testing on the Thermal Standard, the alumina disk was replaced by the same thermal insulation used during ASC-E2 thermal barrier testing. The Thermal Standard was then run through a range of HSTs with no rod in place.

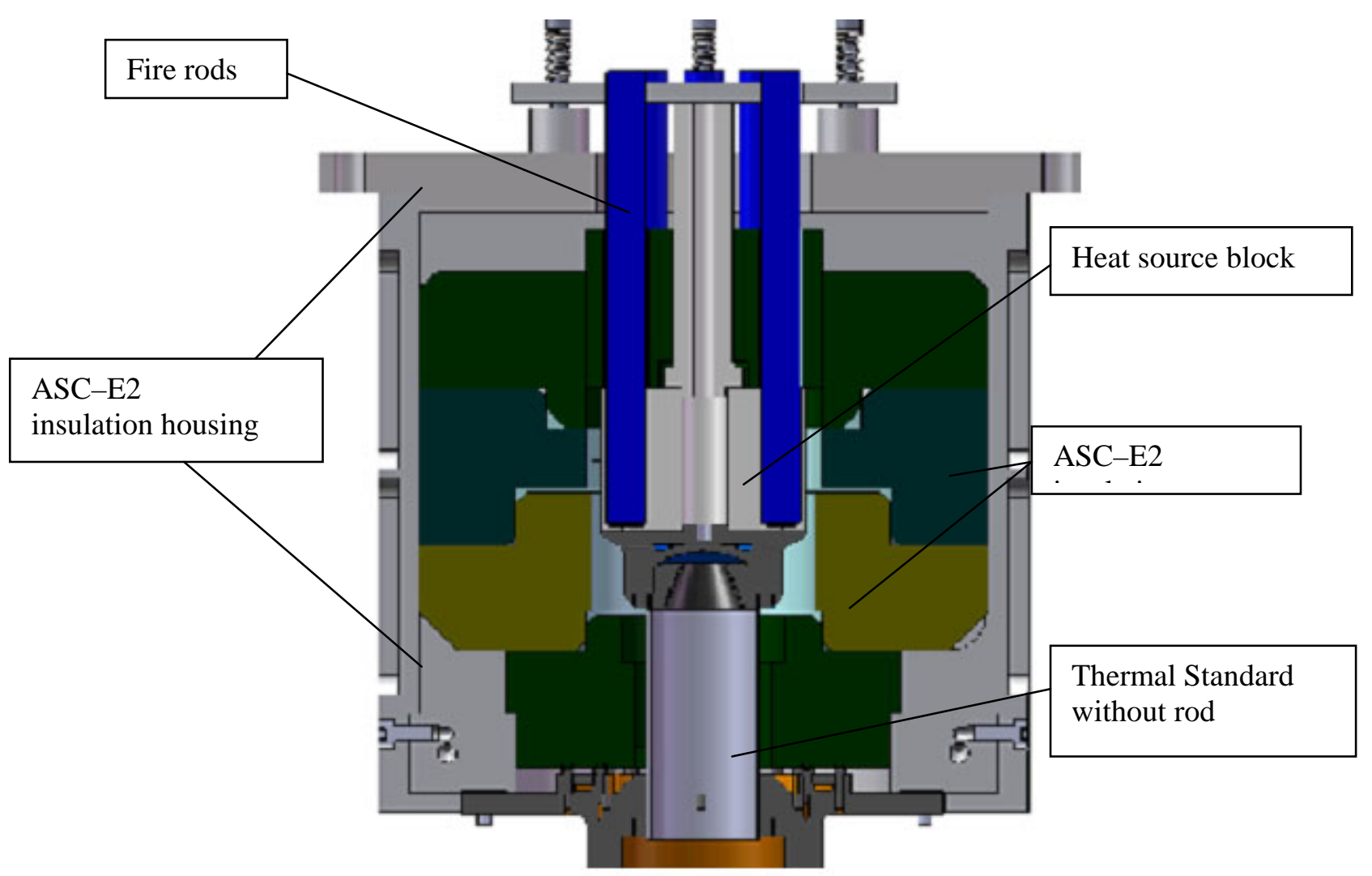

Figure 3.-Cross-section of the Thermal Standard in the simulated non-operating configuration. 


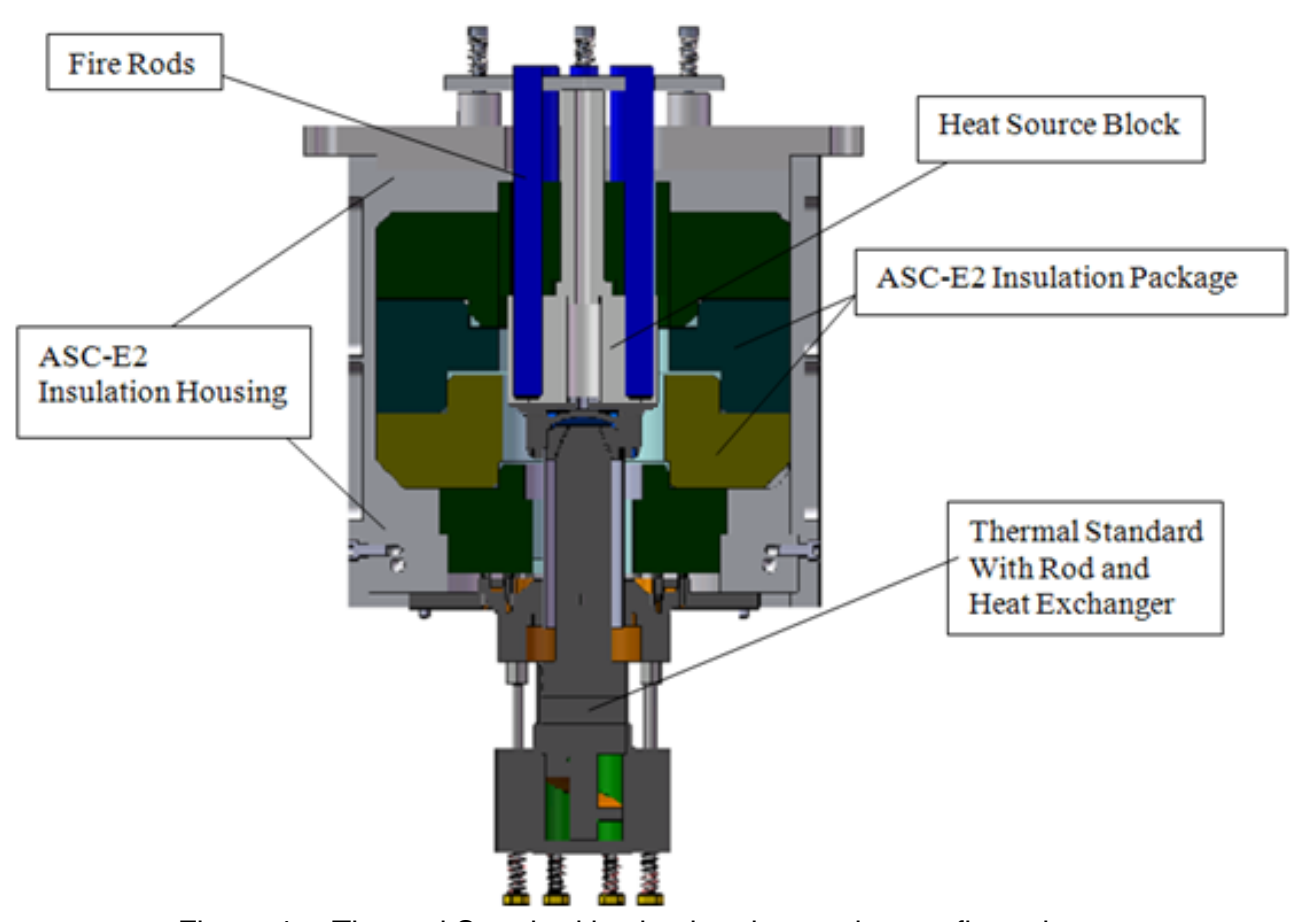

Figure 4.--Thermal Standard in simulated operation configuration.

TABLE 1.-COMPARISON OF ASC-E2 AND THERMAL STANDARD TEST SEQUENCES

\begin{tabular}{|c|l|c|l|l|l|l|l|}
\hline \multicolumn{4}{|c|}{ ASC-E2 convertor } & \multicolumn{3}{c|}{ Thermal standard } \\
\hline Test title & $\begin{array}{l}\text { Interface } \\
\text { material }\end{array}$ & $\begin{array}{l}\text { Piston } \\
\text { status }\end{array}$ & $\begin{array}{l}\text { EL calculation } \\
\text { method }\end{array}$ & Test title & $\begin{array}{l}\text { Interface } \\
\text { material }\end{array}$ & $\begin{array}{l}\text { Rod/No } \\
\text { rod }\end{array}$ & EL calculation method \\
\hline Alumina disk & $\begin{array}{l}\text { Alumina } \\
\text { disk }\end{array}$ & Stalled & $\begin{array}{l}\text { Conduction } \\
\text { calculation }\end{array}$ & $\begin{array}{l}\text { Simulated } \\
\text { alumina disk }\end{array}$ & $\begin{array}{l}\text { Alumina } \\
\text { disk }\end{array}$ & No rod & $\begin{array}{l}\text { Conduction } \\
\text { calculation }\end{array}$ \\
\hline $\begin{array}{l}\text { Thermal } \\
\text { barrier }\end{array}$ & $\begin{array}{l}\text { Ceramic } \\
\text { paper }\end{array}$ & Stalled & $\begin{array}{l}\text { Conduction } \\
\text { calculation }\end{array}$ & $\begin{array}{l}\text { Simulated } \\
\text { thermal barrier }\end{array}$ & $\begin{array}{l}\text { Ceramic } \\
\text { paper }\end{array}$ & No rod & $\begin{array}{l}\text { Conduction } \\
\text { calculation }\end{array}$ \\
\hline $\begin{array}{l}\text { Nominal } \\
\text { operation }\end{array}$ & $\begin{array}{l}\text { Alumina } \\
\text { disk }\end{array}$ & Moving & $\begin{array}{l}\text { Correlation based } \\
\text { on Alumina disk } \\
\text { thermal barrier } \\
\text { testing }\end{array}$ & $\begin{array}{l}\text { Simulated } \\
\text { nominal } \\
\text { operation }\end{array}$ & $\begin{array}{l}\text { Alumina } \\
\text { disk }\end{array}$ & Rod-in & $\begin{array}{l}\text { Correlation based on } \\
\text { alumina disk/thermal } \\
\text { barrier testing and } \\
\text { conduction calculation }\end{array}$ \\
\hline
\end{tabular}

Following alumina disk testing and/or thermal barrier testing at GRC, ASC-E2 convertors are typically run at some nominal operating condition and empirical correlations are used to predict the NHI of the convertor in real time. To simulate an operating convertor, the Thermal Standard was run with a rod in place, as shown in Figure 4. The rod was insulated from the heater head wall to prevent radial heat transfer that would invalidate the use of one-dimensional heat flow calculations. In this configuration, the temperature profile on the wall and the rod were measured, and Fourier's law is once again used to determine both the heat conducted through the wall and the heat conducted through the rod, and the sum of these two is analogous to the NHI into an ASC-E2 convertor. The difference between the GHI, and the sum of the heat through the rod, and the heat through the heater head wall is then calculated was the EL.

Empirical models were validated by using the correlations based on simulated non-operating data (with no rod in place) to predict the EL during simulated operation (with rod in place). The NHI was then calculated as the difference between the measured GHI and the predicted EL. These values are then compared to the sum of the values for heat input through the rod and the heater head as calculated from measured temperature gradients on the Thermal Standard hardware to validate models and to quantify bias and error introduced by the correlations. Table 1 summarizes the ASC-E2 thermal loss test sequence and the Thermal Standard simulation method for each test. 


\subsection{Results}

\subsection{Replication of ASC-E2 Behavior}

It is not necessary to have an exact replica of ASC-E2 to validate a modeling method, but the validation is certainly more applicable the closer the Thermal Standard is to an ASC-E2 heater head. Although the Thermal Standard design is very similar to the ASC-E2 heater head design, there are differences in materials and internal geometry. It is therefore useful to compare data from the Thermal Standard data taken on ASC-E2 convertors. Comparisons of Thermal Standard simulated operating data and actual ASC-E2 operating data are difficult to make because NHI cannot be directly measured on operating convertors, however comparisons of EL can be made to non-operating convertors using alumina disk and thermal barrier data.

Figures 5 through 8 show comparisons Thermal Standard data with no rod in place compared to thermal barrier and alumina disk data from various ASC-E2 convertors. Thermal barrier data was collected on five convertors, while alumina disk data was collected on three convertors. As shown in Figure 6, the relationship between HST and EL appears to be well within the range of what is expected of a convertor during thermal barrier testing, comparing very well with what was observed on ASC-E2 \#3 and \#4. Likewise, Figure 7 shows that the relationship between HST and HET during thermal barrier testing. Thermal Standard again appears to be well within the range of what is seen during thermal barrier testing on ASC-E2 convertors.

Figure 7 shows a comparison between alumina disk data taken on the Thermal Standard and alumina disk data taken on various convertors. The Thermal Standard EL are lower than those seen on ASC-E2 \#5 and \#6 by approximately $7 \mathrm{~W}$. This is not surprising because the EL calculated for the Thermal Standard were also approximately $7 \mathrm{~W}$ lower than those of ASC-E2 \#5 and \#6 during thermal barrier testing, as shown in Figure 6. Figure 8 shows the relationship between HET and HST for the Thermal Standard compared to various convertors. The difference between the HST and HET on the Thermal Standard is larger than what is seen on the ASC-E2 convertors by approximately $9^{\circ}$. This is likely caused by more heat flowing through the thicker, constant wall thickness of the Thermal Standard heater head compared to the thinner variable thickness wall of the ASC-E2 convertors.

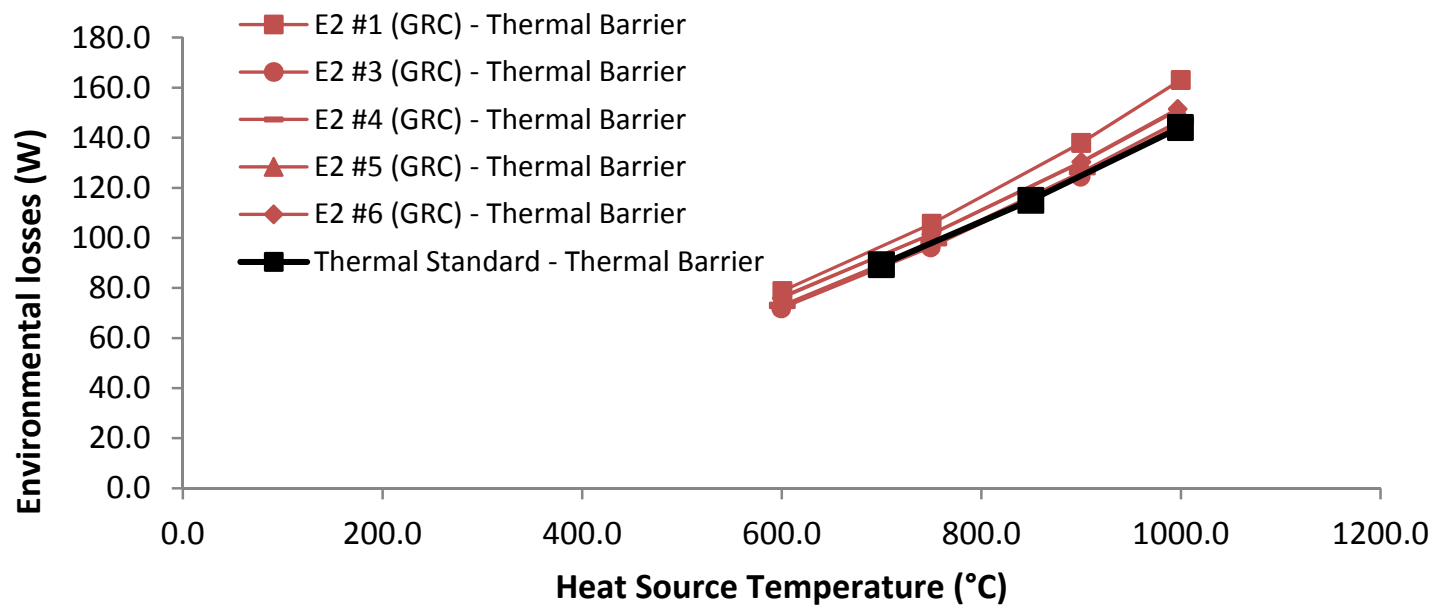

Figure 5.-Environmental losses of Thermal Standard compared to ASC-E2 convertors during thermal barrier testing. 


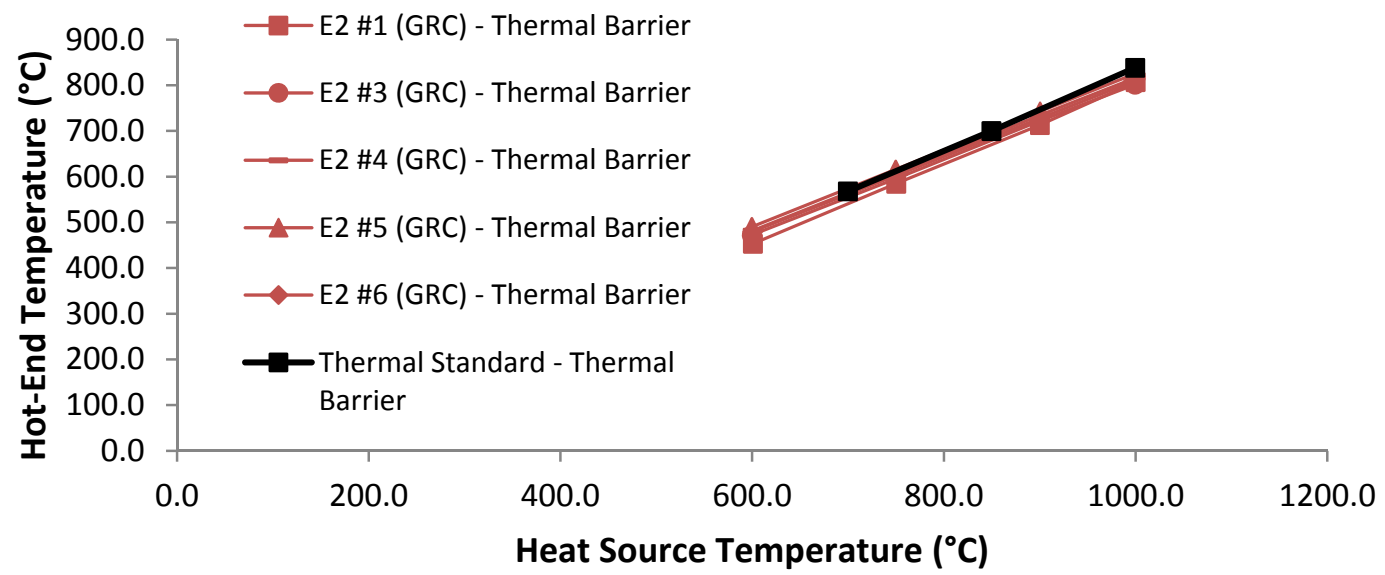

Figure 6.-Relationship between hot-end and heat source temperature on the Thermal Standard and ASC-E2 convertors during thermal barrier testing.

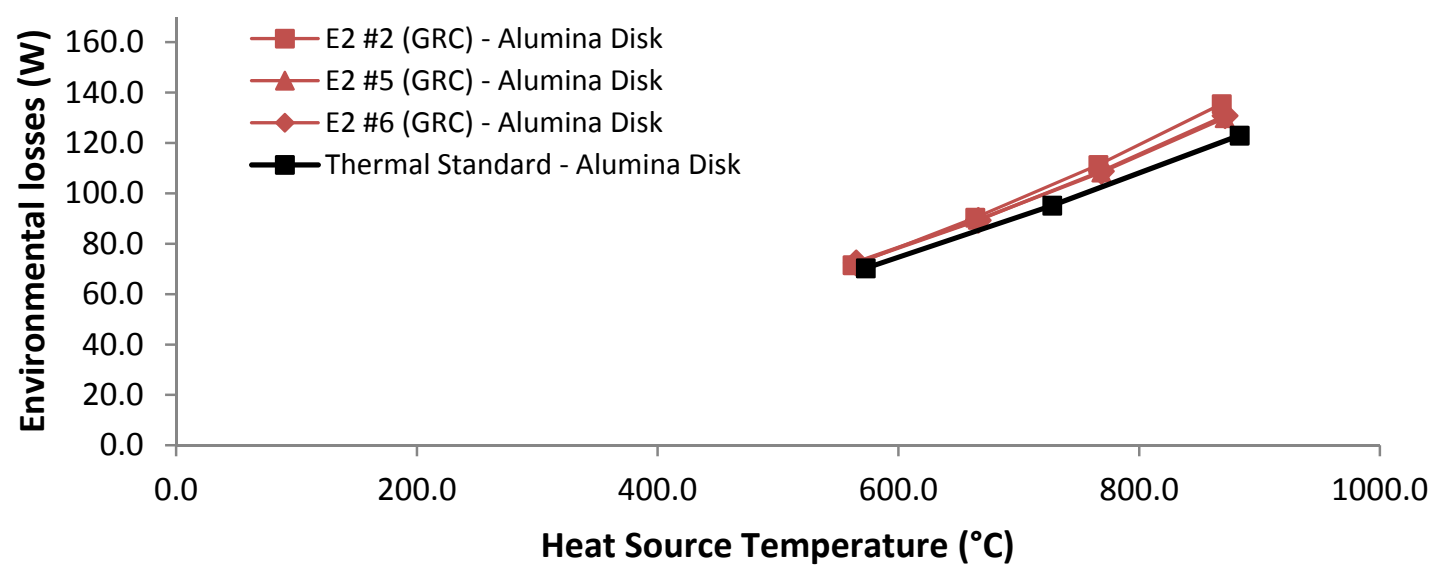

Figure 7.-Environmental losses of Thermal Standard compared to ASC-E2 convertors during alumina disk testing.

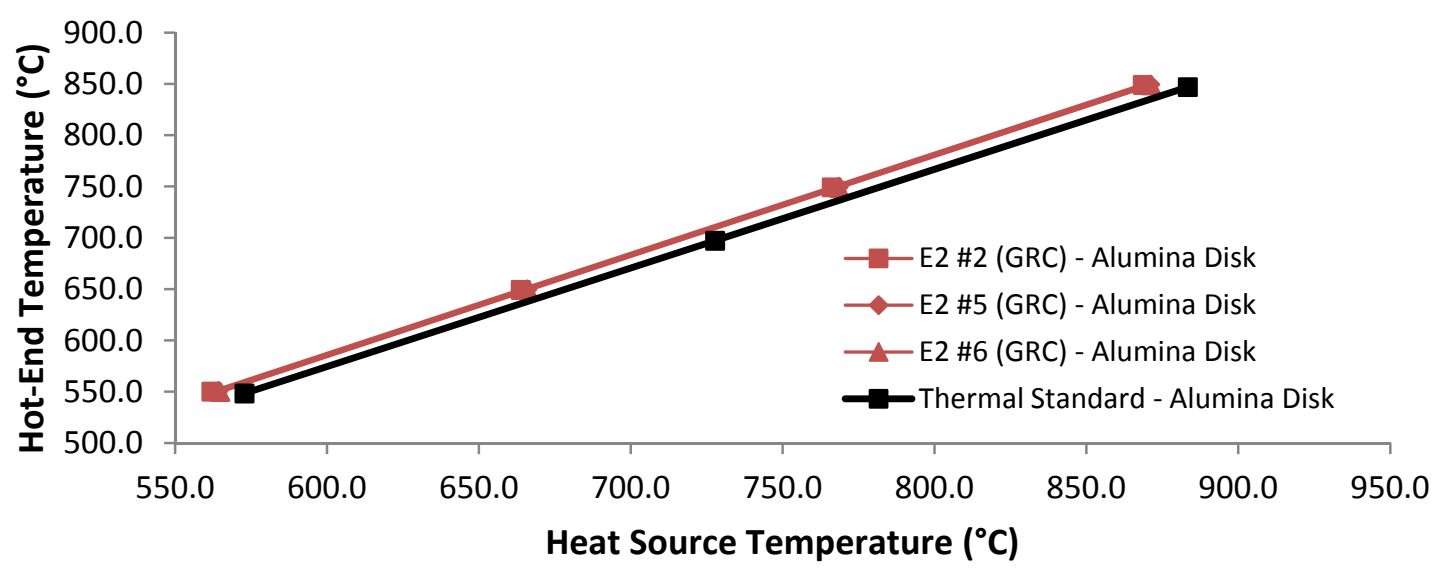

Figure 8.-Relationship between hot-end and heat source temperature on the Thermal Standard and ASC-E2 convertors during alumina disk testing. 
The Thermal Standard replicates the trends in both EL and HET versus HST for both alumina disk and thermal barrier testing. In addition to matching trends, the Thermal Standard matches the absolute value of both HET and EL test data when plotted against HST for ASC-E2 convertors during thermal barrier testing. The absolute value of EL and HET plotted against HST are within $7 \mathrm{~W}$ and $9{ }^{\circ} \mathrm{C}$, respectively, of ASC-E2 test data taken during alumina disk testing. The matching of trends, as well as modest differences in absolute values of characterizing parameters suggests that the Thermal Standard sufficiently mimics the characteristics of an ASC-E2 convertor and can be used to validate empirical correlations as well as numerical models.

\subsection{Combined Thermal Barrier and Alumina Disk Correlations}

When analyzing thermal barrier and alumina disk datasets independently, the approximate relationship between the HET and the HST is given by:

$$
\mathrm{HET} \sim \mathrm{HST}-(\mathrm{NHI})(\mathrm{R})
$$

where $\mathrm{R}$ is the thermal resistance between the heat source and the hot end. Because the thermal resistance is close to constant within a given test (it is approximately equal to either the alumina disk resistance or the thermal barrier resistance depending on the test), and the NHI is itself correlated to the HST, there is a strong cross correlation between the HET and the HST, which can be seen in Figures 6 and 8. This cross correlation masks the fact that one parameter may actually be more strongly correlated to EL than the other.

Analyzing alumina disk data and thermal barrier data together decouples the HET from the HST because different thermal resistances are used in each test, making it easier to distinguish how they independently effect the EL. Figures 9 and 10 show the heat source and hot-end best fit curves, respectively, plotted against the combined alumina disk and thermal barrier EL. These figures show how well each correlation parameter fits simulated non-operating data, they do not show how well the correlations do at predicting the environmental losses during simulated operation. The comparison to simulated operating data can be found in the results section of this paper.

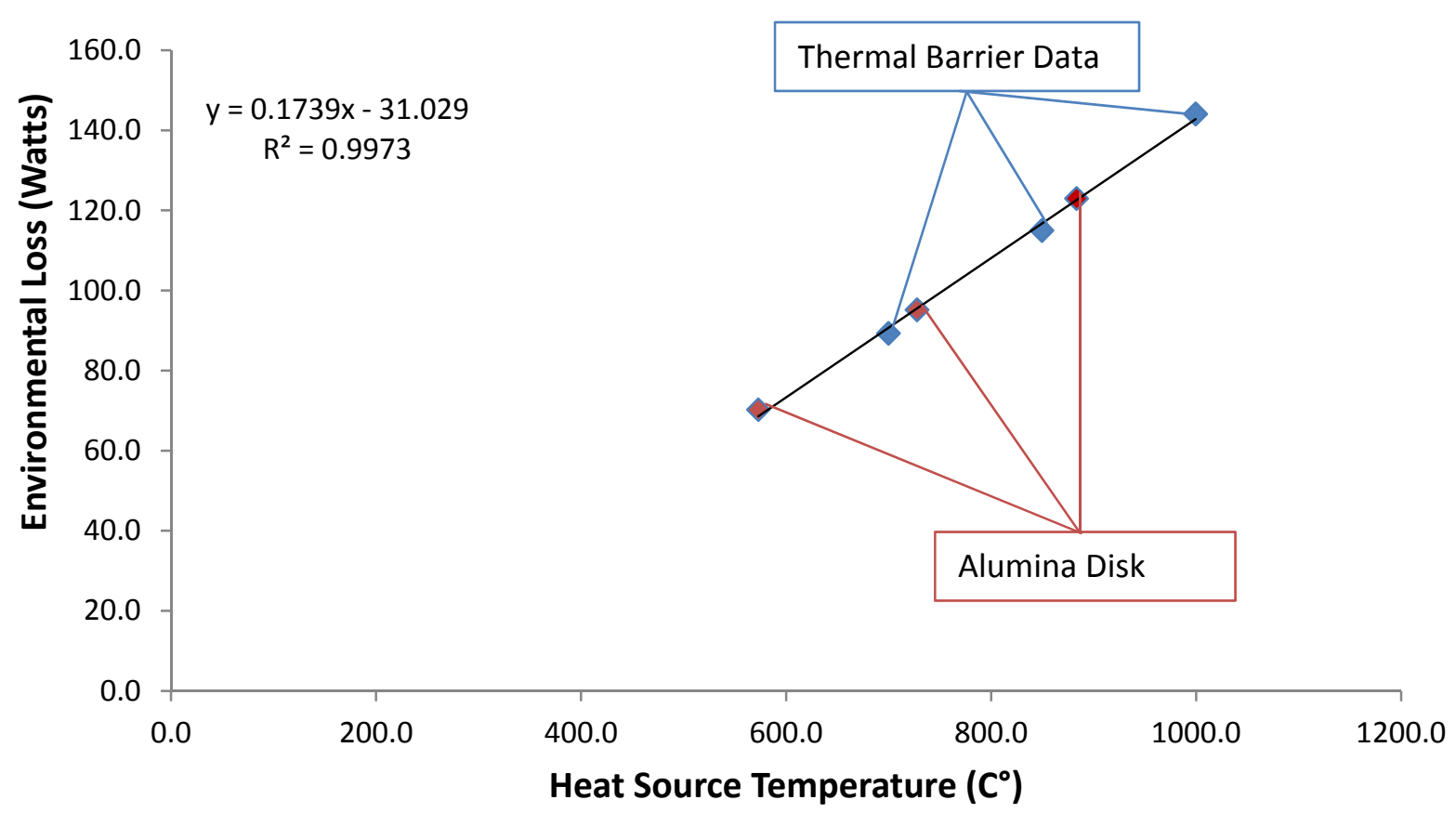

Figure 9.-Goodness of fit of a heat source temperature correlation fit to combined alumina disk and thermal barrier testing (simulated non-operating data). 


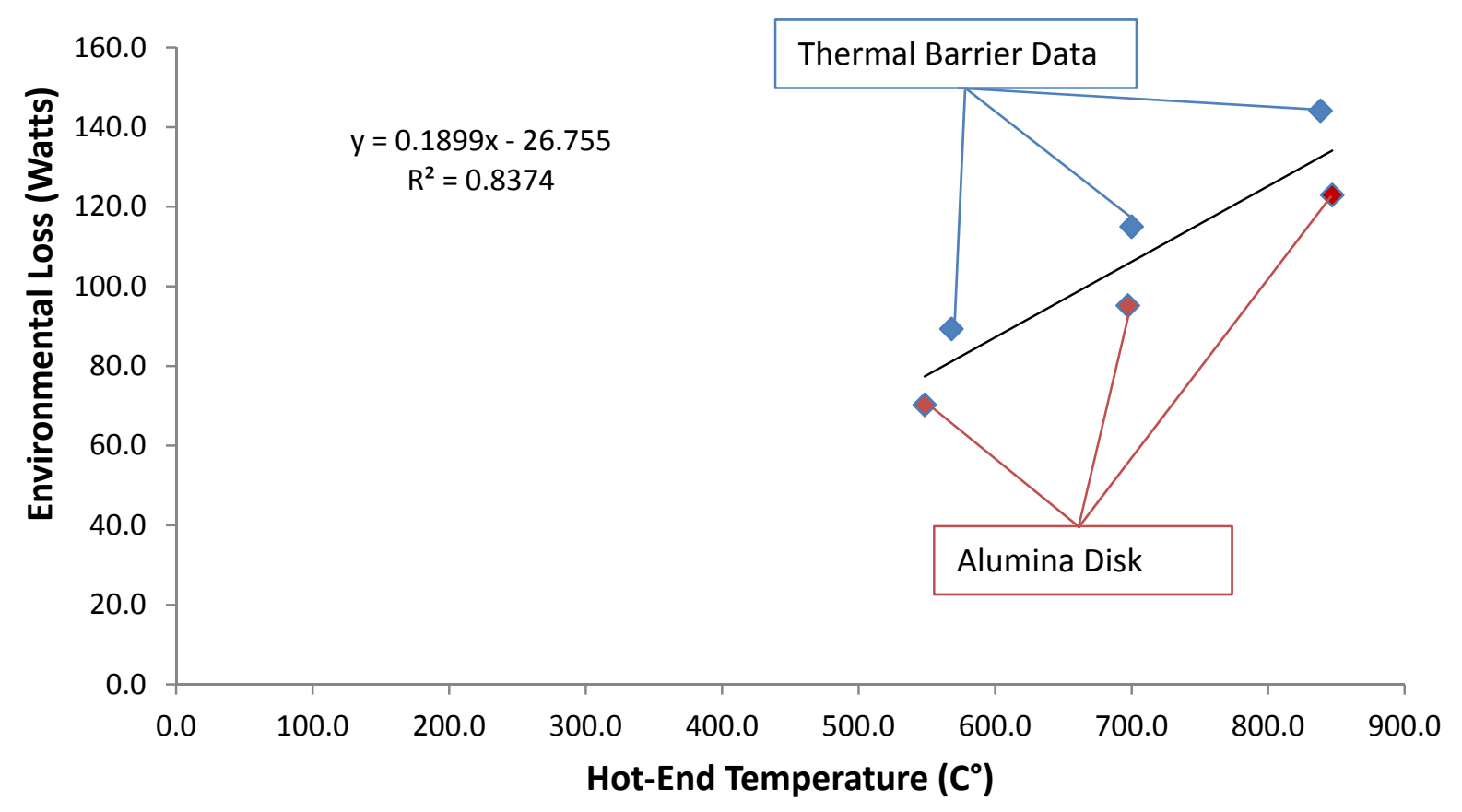

Figure 10.-Goodness of fit of a hot-end temperature correlation fit to combined alumina disk and thermal barrier testing (simulated non-operating data).

The heat-source-based correlation fits the combined alumina disk and thermal barrier data far better than the hot-end correlation. The fact that two distinct sets of points are present (one for thermal barrier and one for alumina disk) when using a HET correlation suggests that Equation (1) is not valid when considering HET as the only correlation parameter. This is not always obvious because when the alumina disk and thermal barrier datasets are considered individually the cross-correlation between HET and HST can mask the fact that HET alone does not adequately correlate with EL. Conversely, the fact that both alumina disk points and thermal barrier points lie close to a single curve when plotted versus HST suggests Equation (1) is valid when correlations are built on HST alone. It also suggests that it may be unnecessary to perform both thermal barrier and alumina disk testing to generate HST correlations.

These conclusions might lead one to suspect that the HST-based correlations would be a better predictor of EL and NHI during simulated operation than HET correlations. However, when these two models are used to predict EL for simulated operation, as shown in Figures 11 and 12, the heat source correlation overpredicts EL by $14.8 \mathrm{~W}$ on average, while the correlation based on HET correlation underpredicts EL by $3.8 \mathrm{~W}$ on average. A line of slope equal to one and intercept equal to zero represents a perfect model, and is plotted for reference.

Although the HET correlations have been shown, in this case, to be more accurate predictors of the EL than the HST correlations, it is highly recommended that HET correlations not be used to predict the EL of operating ASC-E2 convertors. The ability of these correlations to fit Thermal Standard data accurately is likely coincidental. It is highly unlikely that HET correlations will generalize to different values of piston amplitude and GHI when applied to operating ASC-E2 convertors.

For example, if an ASC-E2 convertor operating at a constant HET underwent a piston amplitude increase, the GHI and the HST would both increase. If the correlation used to calculate EL in Equation (2) only considers HET then the estimated EL would not change and the net heat input would be equal to the change in gross heat input. However, this analysis ignores the fact that the HST has also increased, resulting in an increase in environmental losses, and Figure 10 shows that ignoring changes in the HST can result in substantial errors in the calculation of EL and corresponding errors in the calculation of net heat input. Therefore, it is recommended that the HST be used in all single parameter environmental loss correlations and HET correlations are not discussed further in this paper. 


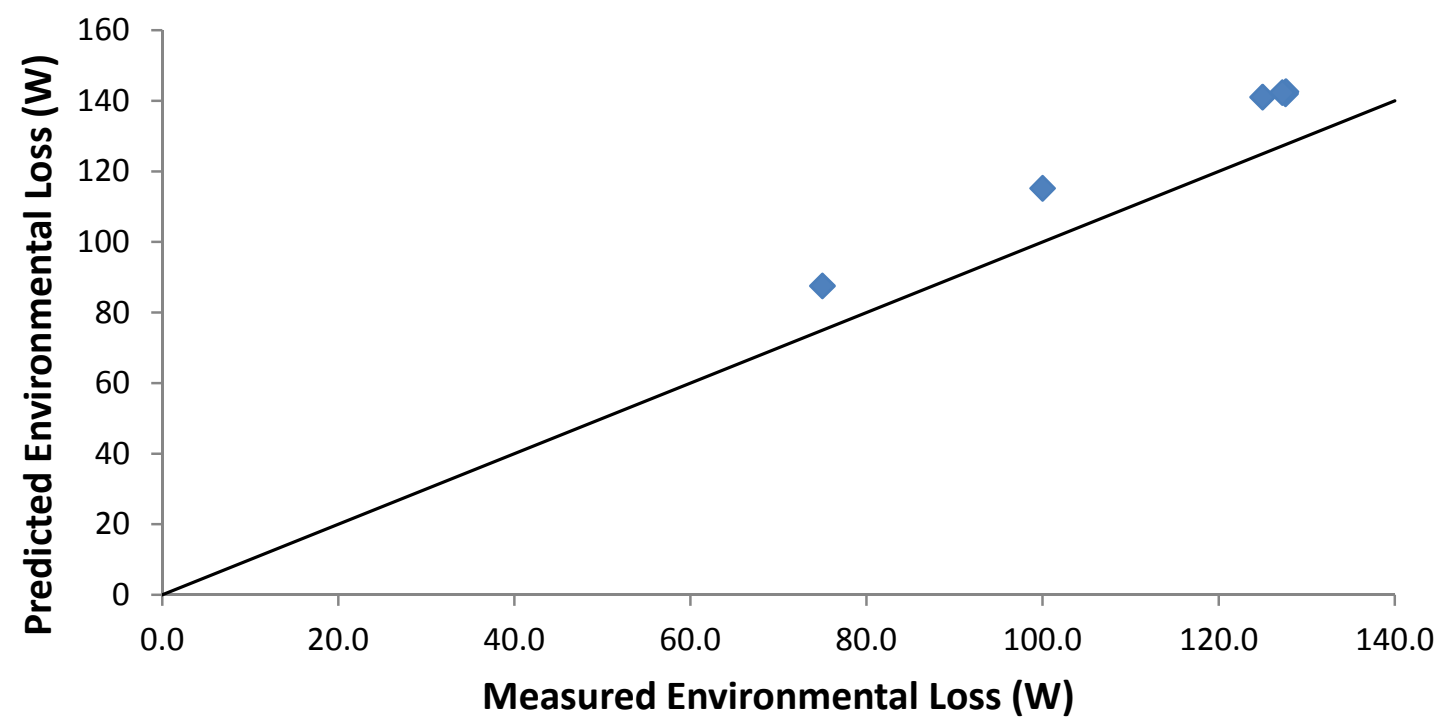

Figure 11.--Predicted vs. measured environmental losses for simulated operation using heat source temperature correlation based on alumina disk and thermal barrier data.

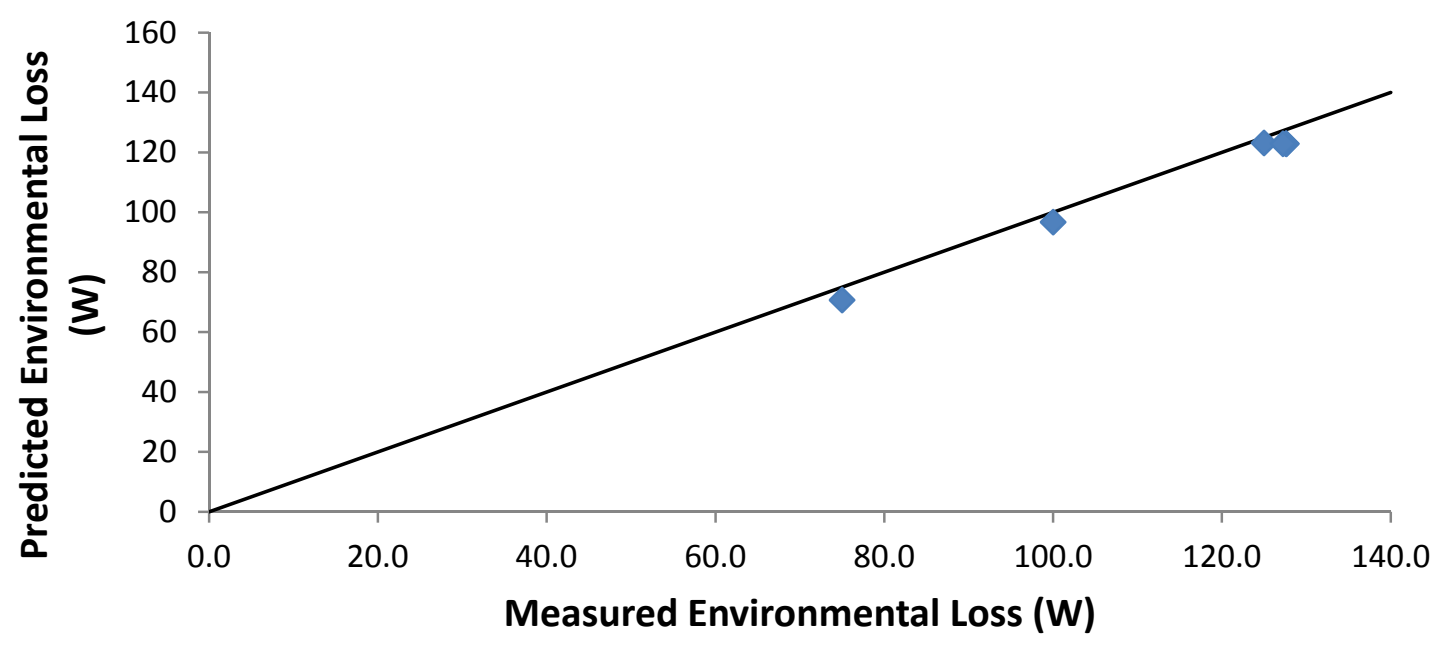

Figure 12.--Predicted vs. measured environmental losses for simulated operation using hot-end temperature correlation based on alumina disk and thermal barrier data. 
When using heat source correlations based on combined thermal barrier and alumina disk testing to predict the EL during simulated operation, the difference term as described by Equation (2) is $14.8 \mathrm{~W}$. If this bias is tolerable, then these correlations can be used directly. If not, it may be possible to take advantage of the fact that this difference is unidirectional bias and not random scatter, to calculate a more accurate value. Equation (2) could be modified to include the estimated bias as calculated during thermal standard testing

$$
\mathrm{EL}_{\text {operating ASC }}=\mathrm{f}(\mathrm{HST})_{\text {non-operating ASC }}+(\text { Estimated Bias })_{\text {Thermal Standard }}
$$

This would allow environmental loss correlations based on ASC-E2ASC-E2 operating data to be corrected by an estimated bias from Thermal Standard testing, potentially producing a more accurate result. However, this must be done with caution because it uses an unverifiable assumption that the bias seen during Thermal Standard testing is similar to what would be seen on ASC-E2 convertors. Since the Thermal Standard closely mimics the behavior of an operating convertor, this does not appear to be a bad assumption, but it is an unverifiable assumption.

Another technique previously used to build correlations for ASC-E2 convertors was to use weighted average temperatures or a multi-parameter fit, using both hot-end and HST as correlation parameters. The weighting that fits the combined alumina disk and thermal barrier datasets best was a 93 percent heat source weighting and a 7 percent hot-end weighting. This correlation offers some improvement over the heat-source-only correlation; again it overpredicts EL, this time by $13.5 \mathrm{~W}$ on average.

Using a weighted average or multi-parameter fit is not recommended unless both alumina disk and thermal barrier data are both available because of the strong cross correlation between hot-end and HST that exists when only one or the other data set is available. Multi-parameter fits based on highly cross correlated data can inappropriately magnify, reduce, or ignore the contributions of certain parameters.

\subsection{Alumina Disk Correlations}

As described previously, alumina disk correlations based on HST are expected to overpredict EL of operating convertors because correlations based on HST assume that the heat source and HET are both close to the higher HST. Figure 13 is a plot of predicted EL from the alumina disk HST correlation against the Thermal Standard measured EL. On average, the heat source model overpredicted environmental loss by $13.9 \mathrm{~W}$, which would result in an underprediction of $\mathrm{NHI}$ of the same amount. This test confirms and quantifies the intuitive suspicion that heat-source-based correlations build on alumina disk data overpredict EL.

\subsection{Thermal Barrier Correlations}

Correlations based on thermal barrier testing are expected to have less error than correlations based on alumina disk testing because the relationship between hot-end and HST is closer to what is seen on operating convertors, and because these correlations eliminate the need for extrapolation. Figure 14 is a plot of predicted EL from a HST correlation using thermal barrier data against the Thermal Standard measured EL. Heat source correlations based on thermal barrier data alone were found to overpredict EL by $14.1 \mathrm{~W}$ on average, showing no substantial improvement over the predictions based on alumina disk testing. 


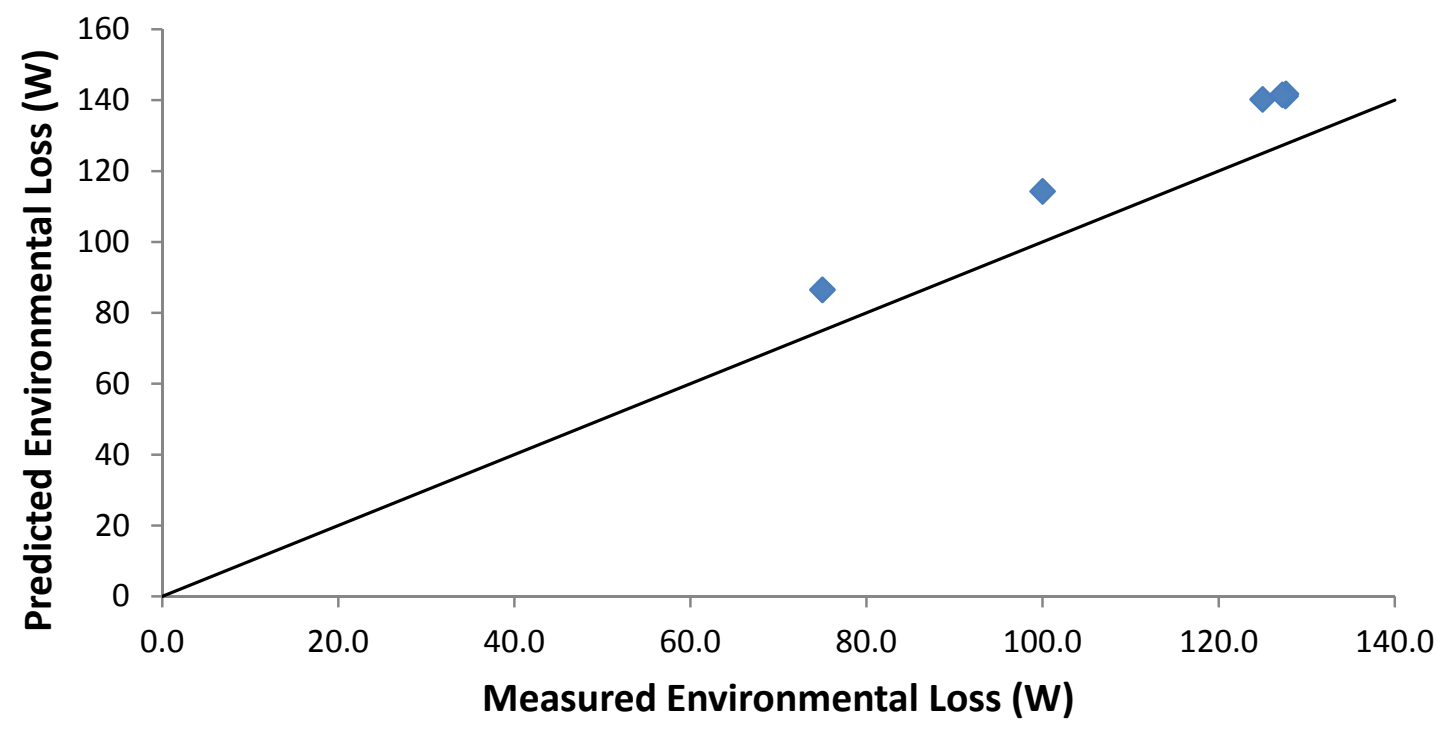

Figure 13.--Predicted environmental losses vs. measured environmental losses for a heat source temperature correlation based on alumina disk testing.

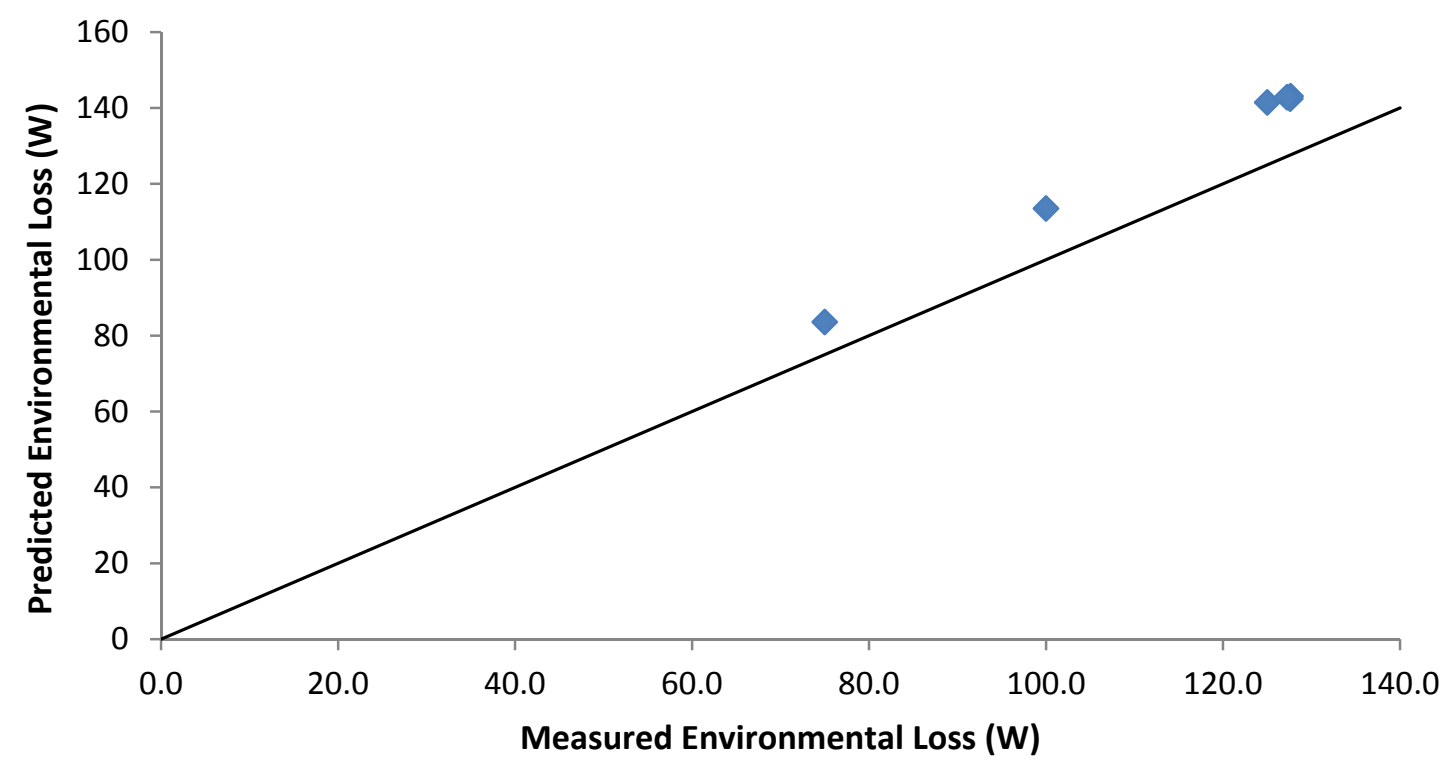

Figure 14.--Predicted environmental losses vs. measured environmental losses for a heat source temperature correlation based on thermal barrier testing. 


\subsection{Conclusions}

The Thermal Standard was used to scrutinize the methods used at NASA Glenn to calculate the net heat input of the ASC-E2 convertor using empirical correlations. In order for these methods to be considered acceptable, the correlation parameters must adequately correlate to the EL of a non-operating convertor (i.e., Eq. (1) must be valid), and correlations based on non-operating data must be applicable to operating convertors (i.e., the Difference term in Eq. (2) must be sufficiently small).

The validity of Equation (1) was tested by considering both thermal barrier and alumina disk datasets simultaneously, which eliminated the cross correlation between the HET and the HST. This analysis showed that Equation (1) is not valid when using HET as the only correlation parameter. Considering only HET and ignoring the effects of HST, resulted in poor correlations when analyzing combined thermal barrier and alumina disk data. This analysis also showed that Equation (1) is valid when using HST as the only correlation parameter. Based on this, it is recommended that the HST be the only parameter used in single-parameter correlations on ASC-E2 convertors. Alternatively, a multi-parameter correlation, or weighted average temperature correlation can be used, but only if both alumina disk and thermal barrier datasets are available, otherwise cross correlation between the hot-end and HSTs is too high to accurately distinguish their independent contributions to EL. For the Thermal Standard, the optimal weighting for the weighted average temperature based on combined alumina disk and thermal barrier data was 93 percent HST and 7 percent HET, once again showing the dominance of the heat source in the environmental loss correlations.

Thermal barrier and alumina disk data were shown to collapse onto a single curve when plotted against HST, which suggested that conducting thermal barrier and alumina disk tests may be redundant if a correlation based only on heat-source temperature will be used. Because alumina disk testing does not require disassembly of the insulation package, it may be advantageous to build correlations based on alumina disk testing only.

The difference term in Equation (2) was quantified for HST correlations based on thermal barrier testing, alumina disk testing, and both tests combined. HST correlations based on thermal barrier data were shown to underpredict net heat input by $14.1 \mathrm{~W}$ on average. HST correlations based on alumina disk data were shown to underpredict net heat input by $13.9 \mathrm{~W}$ on average. HST correlations based on combined thermal barrier and alumina disk data was shown to underpredict net heat input by $14.8 \mathrm{~W}$ on average. A weighted average temperature correlation based on combined thermal barrier and alumina disk data was shown to underpredict net heat input by $13.5 \mathrm{~W}$ on average.

The difference term associated with each of these correlations appears as unidirectional bias, not random scatter. Therefore, if the difference terms quantified above are not small enough to be considered useful, it is possible that the unidirectional bias measured during Thermal Standard testing could be applied the NHI correlations used on operating ASC-E2 convertors. However, this assumes that the bias measured during Thermal Standard testing is close the bias that would be seen on an operating convertor, which cannot be verified.

\section{References}

1. Reid, T., et al., "Computational Methodology for Simulating Thermal Loss Testing of the Advanced Stirling Convertor,” IECEC 2011, AIAA (submitted for publication)

2. Schifer, N., Briggs, M., "Environmental Loss Characterization of an Advanced Stirling Convertor (ASC-E2) Insulation Package using a Mock Heater,” IECEC 2011, AIAA (submitted for publication)

3. Ellis, David L., and Keller, Dennis J., "Thermophysical Properties of GRCop-84,” NASA/CR-2000-210055, 2000.

4. Ellis, David L., "GRCop-84: A High-Temperature Copper Alloy for High-Heat-Flux Applications,” NASA/TM-2005-213566, 2005. 


\begin{tabular}{|c|c|c|c|c|c|}
\hline \multicolumn{5}{|c|}{ REPORT DOCUMENTATION PAGE } & $\begin{array}{c}\text { Form Approved } \\
\text { OMB No. 0704-0188 }\end{array}$ \\
\hline \multicolumn{6}{|c|}{$\begin{array}{l}\text { The public reporting burden for this collection of information is estimated to average } 1 \text { hour per response, including the time for reviewing instructions, searching existing data sources, gathering and maintaining the } \\
\text { data needed, and completing and reviewing the collection of information. Send comments regarding this burden estimate or any other aspect of this collection of information, including suggestions for reducing this } \\
\text { burden, to Department of Defense, Washington Headquarters Services, Directorate for Information Operations and Reports (0704-0188, } 1215 \text { Jefferson Davis Highway, Suite } 1204 \text {, Arlington, VA } 22202-4302 \text {. } \\
\text { Respondents should be aware that notwithstanding any other provision of law, no person shall be subject to any penalty for failing to comply with a collection of information if it does not display a currently valid OMB } \\
\text { control number. } \\
\text { PLEASE DO NOT RETURN YOUR FORM TO THE ABOVE ADDRESS. }\end{array}$} \\
\hline \multicolumn{2}{|c|}{$\begin{array}{l}\text { 1. REPORT DATE (DD-MM-YYYY) } \\
01-03-2012\end{array}$} & \multicolumn{3}{|c|}{$\begin{array}{l}\text { 2. REPORT TYPE } \\
\text { Technical Memorandum }\end{array}$} & 3. DATES COVERED (From - To) \\
\hline \multirow{3}{*}{\multicolumn{5}{|c|}{$\begin{array}{l}\text { 4. TITLE AND SUBTITLE } \\
\text { Evaluation of Advanced Stirling Convertor Net Heat Input Correlation Methods Using a } \\
\text { Thermal Standard }\end{array}$}} & 5a. CONTRACT NUMBER \\
\hline & & & & & 5b. GRANT NUMBER \\
\hline & & & & & 5c. PROGRAM ELEMENT NUMBER \\
\hline \multirow{3}{*}{\multicolumn{5}{|c|}{$\begin{array}{l}\text { 6. AUTHOR(S) } \\
\text { Briggs, Maxwell, H.; Schifer, Nicholas, A. }\end{array}$}} & 5d. PROJECT NUMBER \\
\hline & & & & & 5e. TASK NUMBER \\
\hline & & & & & $\begin{array}{l}\text { 5f. WORK UNIT NUMBER } \\
\text { WBS 138494.05.02.04.03 }\end{array}$ \\
\hline \multicolumn{5}{|c|}{$\begin{array}{l}\text { 7. PERFORMING ORGANIZATION NAME(S) AND ADDRESS(ES) } \\
\text { National Aeronautics and Space Administration } \\
\text { John H. Glenn Research Center at Lewis Field } \\
\text { Cleveland, Ohio 44135-3191 }\end{array}$} & $\begin{array}{l}\text { 8. PERFORMING ORGANIZATION } \\
\text { REPORT NUMBER } \\
\text { E-17829 }\end{array}$ \\
\hline \multirow{2}{*}{\multicolumn{5}{|c|}{$\begin{array}{l}\text { 9. SPONSORING/MONITORING AGENCY NAME(S) AND ADDRESS(ES) } \\
\text { National Aeronautics and Space Administration } \\
\text { Washington, DC 20546-0001 }\end{array}$}} & $\begin{array}{l}\text { 10. SPONSORING/MONITOR'S } \\
\text { ACRONYM(S) } \\
\text { NASA }\end{array}$ \\
\hline & & & & & $\begin{array}{l}\text { 11. SPONSORING/MONITORING } \\
\text { REPORT NUMBER } \\
\text { NASA/TM-2012-217293 }\end{array}$ \\
\hline \multicolumn{6}{|c|}{$\begin{array}{l}\text { 12. DISTRIBUTIONIAVAILABILITY STATEMENT } \\
\text { Unclassified-Unlimited } \\
\text { Subject Category: } 20 \\
\text { Available electronically at http://www.sti.nasa.gov } \\
\text { This publication is available from the NASA Center for AeroSpace Information, 443-757-5802 }\end{array}$} \\
\hline \multicolumn{6}{|c|}{ 13. SUPPLEMENTARY NOTES } \\
\hline \multicolumn{6}{|c|}{$\begin{array}{l}\text { 14. ABSTRACT } \\
\text { The U.S. Department of Energy (DOE) and Lockheed Martin Space Systems Company (LMSSC) have been developing the Advanced } \\
\text { Stirling Radioisotope Generator (ASRG) for use as a power system for space science missions. This generator would use two high- } \\
\text { efficiency Advanced Stirling Convertors (ASCs), developed by Sunpower Inc. and NASA Glenn Research Center (GRC). The ASCs } \\
\text { convert thermal energy from a radioisotope heat source into electricity. As part of ground testing of these ASCs, different operating } \\
\text { conditions are used to simulate expected mission conditions. These conditions require achieving a particular operating frequency, hot end } \\
\text { and cold end temperatures, and specified electrical power output for a given net heat input. In an effort to improve net heat input predictions, } \\
\text { numerous tasks have been performed which provided a more accurate value for net heat input into the ASCs, including testing validation } \\
\text { hardware, known as the Thermal Standard, to provide a direct comparison to numerical and empirical models used to predict convertor net } \\
\text { heat input. This validation hardware provided a comparison for scrutinizing and improving empirical correlations and numerical models of } \\
\text { ASC-E2 net heat input. This hardware simulated the characteristics of an ASC-E2 convertor in both an operating and non-operating mode. } \\
\text { This paper describes the Thermal Standard testing and the conclusions of the validation effort applied to the empirical correlation methods } \\
\text { used by the Radioisotope Power System (RPS) team at NASA Glenn. }\end{array}$} \\
\hline \multicolumn{6}{|c|}{$\begin{array}{l}\text { 15. SUBJECT TERMS } \\
\text { Stirling cycle; Stirling engines; Thermodynamic efficiency; Energy conversion efficiency; Regression analysis }\end{array}$} \\
\hline \multicolumn{3}{|c|}{ 16. SECURITY CLASSIFICATION OF: } & $\begin{array}{l}\text { 17. LIMITATION OF } \\
\text { ABSTRACT }\end{array}$ & $\begin{array}{l}\text { 18. NUMBER } \\
\text { OF }\end{array}$ & $\begin{array}{l}\text { 19a. NAME OF RESPONSIBLE PERSON } \\
\text { STI Help Desk (email:help@sti.nasa.gov) }\end{array}$ \\
\hline $\begin{array}{l}\text { a. REPORT } \\
\text { U }\end{array}$ & $\begin{array}{l}\text { b. ABSTRACT } \\
\text { U }\end{array}$ & $\begin{array}{l}\text { c. THIS } \\
\text { PAGE } \\
\text { U }\end{array}$ & UU & $\begin{array}{l}\text { PAGES } \\
20\end{array}$ & $\begin{array}{l}\text { 19b. TELEPHONE NUMBER (include area code) } \\
443-757-5802\end{array}$ \\
\hline
\end{tabular}



